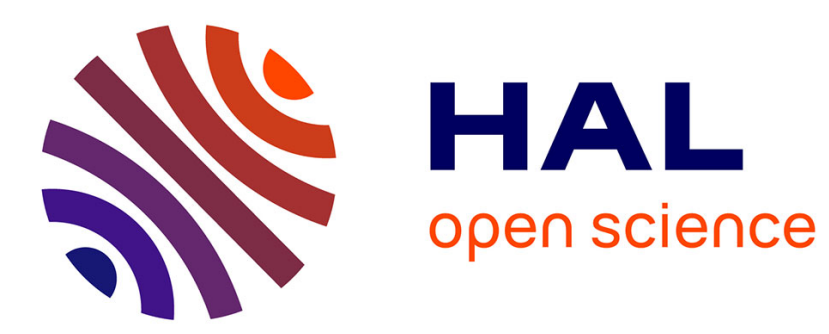

\title{
Magnetic resonance imaging application to study of porous media
}

\author{
O. Lamrous, D. Houi, C. Zarcone, J. Pradere
}

\section{To cite this version:}

O. Lamrous, D. Houi, C. Zarcone, J. Pradere. Magnetic resonance imaging application to study of porous media. Revue de Physique Appliquée, 1989, 24 (5), pp.607-612. 10.1051/rphysap:01989002405060700 . jpa-00246085

\section{HAL Id: jpa-00246085 https://hal.science/jpa-00246085}

Submitted on 1 Jan 1989

HAL is a multi-disciplinary open access archive for the deposit and dissemination of scientific research documents, whether they are published or not. The documents may come from teaching and research institutions in France or abroad, or from public or private research centers.
L'archive ouverte pluridisciplinaire HAL, est destinée au dépôt et à la diffusion de documents scientifiques de niveau recherche, publiés ou non, émanant des établissements d'enseignement et de recherche français ou étrangers, des laboratoires publics ou privés. 


\title{
Magnetic resonance imaging application to study of porous media
}

\author{
O. Lamrous ( $\left.{ }^{1}\right)$, D. Houi $\left({ }^{2}\right)$, C. Zarcone $\left({ }^{2}\right)$ and J. Pradere $\left({ }^{1}\right)$ \\ (1) Unité des résonances magnétiques du laboratoire de biophysique, Professeur Regis, CHU Rangueil, 31054 \\ Toulouse, France \\ (2) Institut de mécanique des fluides, 2 avenue du Professeur Camille Soula, 31400 Toulouse, France
}

(Reçu le 5 juillet 1988, révisé le 3 janvier 1989, accepté le 20 janvier 1989)

\begin{abstract}
Résumé. - Après avoir qualifié le spectro-imageur Bruker BMT 100 à usage médical à l'étude des milieux poreux, nous avons montré à l'aide d'un milieu modèle qu'il était possible de déterminer les porosités locales et globales. Nous avons ensuite utilisé cet appareil pour étudier le colmatage d'une colonne de billes de verre par une suspension de microparticules. Cette application nous a permis de vérifier que les informations tridimensionnelles sont accessibles par IRM.
\end{abstract}

\begin{abstract}
After characterisation of the medical MRI Bruker BMT 100 scanner in the aim of studying porous media, we showed, by means of a model system that it was possible to determine local and overall porosities. We also used this scanner to study the clogging of a column of glass beads by a suspension of microparticles. This application allowed us to check that 3-D information is accessible by MRI.
\end{abstract}

\section{Introduction.}

Porous media have fragile structures; in order to analyse their physical parameters it is sometimes necessary to use non-destructive and non-invasive techniques of measurement. Among these Nuclear Magnetic Resonance NMR Spectroscopy, has been used by chemists extensively in the study of liquid media. The application of NMR to the study of porous media is developing rapidly through the methodological and technological advances being made. Examples of some of the studies performed are measurement of relaxation time and proton density within pores in investigation into porosity and permeability $[1,2]$, as well as wettability [3]. Jones and Child studied other applications of NMR in the study of fluid flow [4]. It was shown that physical parameters such as Carll and Purcell's sequence echo, which is used in measuring the molecular diffusion coefficient [5], pulsed field gradients, used in determining rate distribution functions [6] and the pore size sedimentary rocks [7] become accessible with NMR.

Magnetic Resonance Imaging (MRI) is new technique used primarily in medecine for obtaining images of living tissues [8]. Its use with porous media completes the NMR data available on their internal structures because of the possibility of 3-D visuali- zation. Other studies have compared different visualization techniques such as optical, ultrasound and $\mathrm{X}$-ray methods, which suggest that the best way to study fluid flow in porous media in 3-D is with MRI [9].

In addition the use of MRI is independent of the choice of medium and also permits visualisation of any slice in any plane with better resolution. In IRM literature it has been noted that there are several applications in petroleum research : the visualization of the porosity differences in some rocks [10], the segregation of two phase fluids (water/oil) [11, 12] and the displacement of non-miscible fluids in crushed media [13].

It should be noted that in these studies :

1) the image resolution is in the millimeter and submillimeter ranges and deals with particles in the media which are significantly smaller than the resolution limits ;

2) no reproductible model for the medium was used or has been proposed in these studies, (the samples studied always being the natural media).

In this study we first explored the capabilities of medical scanner imaging which was not originaly designed for studies of porous media and then we used it to study clogging of a column filled by glass beads with a rilsan microparticle suspension. 


\section{Methods and material.}

Our MRI system uses a Carll-Purcell spin echo method combined with standard two-dimensional Fourier transform technique (2 DFT). Proton NMR images were obtained at $2.35 \mathrm{~T}$ which corresponds to a proton resonance frequency of $100 \mathrm{MHz}$. The diameter of the Bruker supraconducting magnet was $40 \mathrm{~cm}$. We used a positive selection gradient with a $90^{\circ}$ selective $\mathrm{rf}$ pulse. This radient was inversed immediately afterwards to refocus the spin system. At $t e / 2$ a second $180^{\circ}$ selective rf pulse generates a spin echo at time $t e=32 \mathrm{~ms}$. The maximum gradient strength available from each of the $X, Y$ and $Z$ gradient coils was $1 \mathrm{G} / \mathrm{cm}$. This allowed us to obtain a minimal slice thicknesses of $1 \mathrm{~mm}$ with the possibility of changing slice's position as needed. Image resolution was defined by the ratio of the field of view (FOV) to the image size in the read gradient direction which varies in a matrix of $256 \times 256$ between $0.4 \mathrm{~mm}$ et $1 \mathrm{~mm}$. The brightness of each pixel (which varies between 0 and 511) is proportional to the proton density in the sample. The NMR signal depends on the longitudinal relaxation time $T_{1}$ and the transversal time $T_{2}$ which are characterised respectively by the recovery of magnetization to the equilibrium state and the decay of the signal strength in CPMG multiple spin echo experiments. In general, the observed 2 DFT signal is proportional to $T_{2} / T_{1}$ at all points within the slice.

\section{Characteristics of the IRM scanner used.}

SPECTRAL RESOLUTION AND CONTRAST. - We tested three different oils (Osberg, Soltrol, Albef) outside the porous medium. Figure 1 shows spectra obtained after one $45^{\circ}$ pulse. See table $I$ : value for $T_{1}$ and $T_{2}$ are respectively measured by inversion recovery and spin echo sequences.

RESUlTS AND DISCUSSION. - With Osberg we discovered two peaks separated by $5 \mathrm{ppm}$. This chemi-

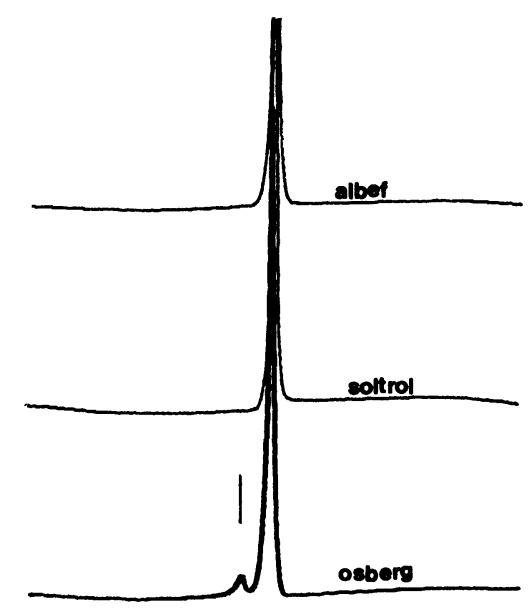

Fig. 1. - Spectra obtained after one $45^{\circ}$ pulse.
Table I. - Values for $T_{1}, T_{2}$ and contrast corresponding for the different oils.

\begin{tabular}{|l|c|c|c|c|}
\hline Oil & $\begin{array}{c}T_{1} \\
(\mathrm{~s})\end{array}$ & $\begin{array}{c}T_{2} \\
(\mathrm{~s})\end{array}$ & $\begin{array}{c}T_{2} / T_{1} \\
(\mathrm{~s})\end{array}$ & $\begin{array}{c}\text { Contraste } \\
10^{6}\end{array}$ \\
\hline Soltrol & 0.98 & 0.81 & 0.82 & 9.61 \\
\hline Albef & 0.13 & 0.09 & 0.38 & 3.23 \\
\hline Osberg & 0.19 & 0.12 & 0.63 & 5.31 \\
\hline
\end{tabular}

cal shift could be responsable for image artefacts [14]. We also noted that the highest $T_{2} / T_{1}$ ratios was with Soltrol and that in this case when the delay time equaled $1 \mathrm{~s}$ we obtained the best image contrast. It was for these reasons that we chose Soltrol to saturate our porous media.

OUR POROUS MEDIUM MODEL. - The porous medium model (Fig. 2) used was composed of polyamide beads ( $3 \mathrm{~mm}$ diameter) covered with Araldite and arranged in a cubic network of $13 \times 13 \times 11$ beads. Its theorical porosity and permeability were 0.476 and $5.10 \mathrm{~m}^{2}$. This structure was saturated with Soltrol and put into a $4 \mathrm{~cm}$ plexiglass cube. We performed sections with images $256 \times 256$ matrix (resolution $0.4 \mathrm{~mm}$ and thickness $3,6,9 \mathrm{~mm}=n \times$ beads diameter). The acquisition time for the image was $13 \mathrm{mn}$.

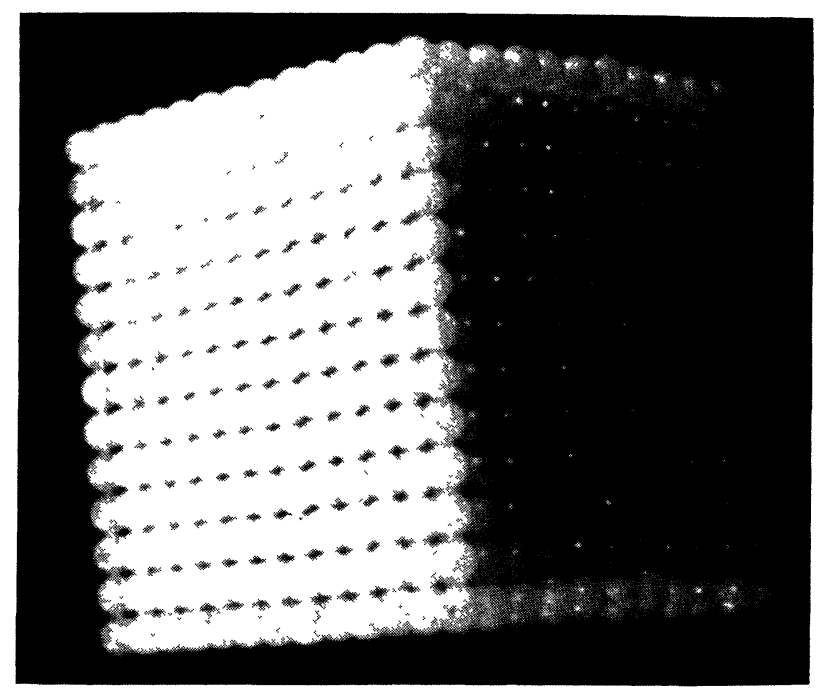

Fig. 2. - Our porous medium model photography.

\section{RESULTS.}

Image analysis. - Image production was noted to be qualitatively good (Fig. 3). We also checked that the brightness profile peaks correspond to the actual presence of pores. Moreover the periodicity of these 


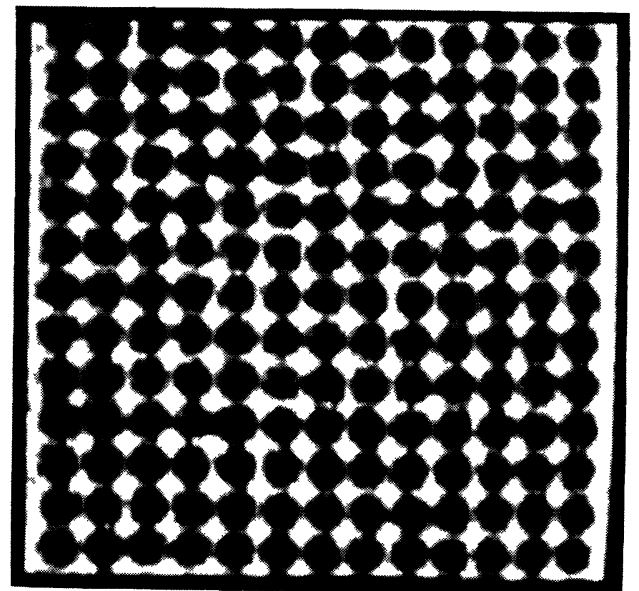

Fig. 3. - IRM section image of the medium model (thickness $=3 \mathrm{~mm}$ ).

profiles shows that the size of the pores is homogeneous in this medium. Using different profiles, corresponding to the center of each row of pores (Fig. 4), we measured the size (e) of the beads in three rows examined for different slice thicknesses (Tab. II). A greater error was found for the thinnest section.

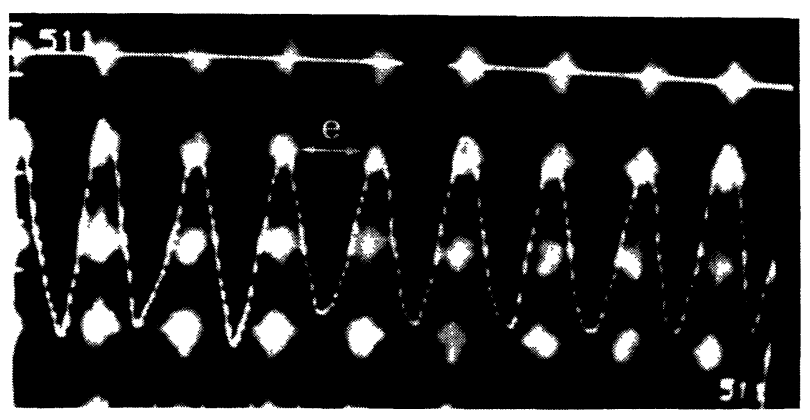

Fig. 4. - Profile corresponding to the center of each row of pores ( $e=$ size of beads).

Table II. - Size of the beads in 3 rows examined for different slice thickness.

\begin{tabular}{|c|c|c|c|c|}
\cline { 2 - 5 } \multicolumn{1}{c|}{} & \multicolumn{4}{|c|}{ Size of the beads (e) } \\
\hline $\begin{array}{c}\text { Slice } \\
\text { thickness } \\
(\mathrm{mm})\end{array}$ & $\begin{array}{c}\text { First } \\
\text { measure } \\
(\mathrm{mm})\end{array}$ & $\begin{array}{c}\text { Second } \\
\text { measure } \\
(\mathrm{mm})\end{array}$ & $\begin{array}{c}\text { Third } \\
\text { measure } \\
(\mathrm{mm})\end{array}$ & $\begin{array}{c}\text { Average } \\
(\mathrm{mm})\end{array}$ \\
\hline 3 & $\begin{array}{c}2.8 \\
(+ \text { or }-0.25)\end{array}$ & $\begin{array}{c}2.9 \\
(+ \text { or }-0.2)\end{array}$ & $\begin{array}{c}3 \\
(+ \text { or }-0.15)\end{array}$ & $\begin{array}{c}2.9 \\
(+ \text { or }-0.2)\end{array}$ \\
\hline 6 & $\begin{array}{c}2.8 \\
(+ \text { or }-0.22)\end{array}$ & $\begin{array}{c}2.9 \\
(+ \text { or }-0.2)\end{array}$ & $\begin{array}{c}3 \\
(+ \text { or }-0.1)\end{array}$ & $\begin{array}{c}2.9 \\
(+ \text { or }-0.17)\end{array}$ \\
\hline 9 & $\begin{array}{c}2.9 \\
(+ \text { or }-0.1)\end{array}$ & $\begin{array}{c}3 \\
(+ \text { or }-0.1)\end{array}$ & $\begin{array}{c}3 \\
(+ \text { or }-0.1)\end{array}$ & $\begin{array}{c}2 / 96 \\
(+ \text { or }-0.1)\end{array}$ \\
\hline
\end{tabular}

MEASUREMENT OF POROSITY BY MRI. - The local theoretical porosities and those measured by MRI are given in figure 5. The MRI measurements were determined by the ratio of the Soltrol density in each $0.4 \times 40 \times 3 \mathrm{~mm}^{3}$ volume element obtained by integration of its signal, to the density of an identical reference volume of porosity 1 taken outside the porous medium. They give an average over estimation of $12 \%$ with respect to theoretical values. The average value of the sum gives a global porosity which is $2 \%$ lower than that calculated theoretically. This difference partly results from proton diffusion inside the pores brought about by field gradients, the presence of glue between the beads and choice of reference brightness level. The high dispersion of the local porosities measured with respect to those calculed can be explained by the difference in magnetic susceptibility caused by the porous medium which brings about a low an variable local field gradient within the pores. This gradient is sufficient to decrease the signal by a few \%. Taking just this effect into account (relaxation effects are ignored) and the difference between the theoretical overall porosity $P_{\mathrm{t}}$ and that measured by MRI $P_{\mathrm{m}}$, we calculated the order of magnitude of the induced gradient :

$$
\Delta G \sim \pm \ln \left(\frac{P_{\mathrm{m}}}{P_{\mathrm{t}}}\right) \frac{1}{\gamma^{2} \delta^{2} a^{2}}= \pm 0.4 \mathrm{mG} / \mathrm{cm}
$$

$a$ is the size of the pores $(3 \mathrm{~mm}), \gamma$ the gyromagnetic ratio and $\delta$ the duration of the gradient $(0.5 \mathrm{~ms})$. At the same time this gradient brings about a error for slice thickness of approximately $0.01 \mathrm{~mm}$. To minimise these effects, it would be necessary to increase the linearity and the intensity of the gradients.

MEASUREMENT OF POROSITY BY NMR. - We measured the overall porosity by the classical methods of weighing and NMR on 4 samples of the same geometrical shape composed of glass beads of various sizes (Tab. III). The NMR measurements were obtained by determining the density of the

Table III. - Weighing and NMR porosities on 4 samples of the same geometrical shape.

\begin{tabular}{|c|c|c|c|}
\hline $\begin{array}{c}\text { Diameter of } \\
\text { the beads }\end{array}$ & $\begin{array}{c}\text { Weight } \\
\text { porosity } \\
\%\end{array}$ & $\begin{array}{c}\text { NMR porosity } \\
\% \\
\text { (average of } \\
10 \text { measures) }\end{array}$ & $\begin{array}{c}\text { Error } \\
\%\end{array}$ \\
\hline 3 & 36.10 & 36.03 & -0.07 \\
\hline 2.3 & 27.10 & 28.20 & 1.1 \\
\hline 3 et 0.5 & 22.20 & 21.90 & -0.3 \\
\hline 1.5 & 34.16 & 33.60 & -0.56 \\
\hline
\end{tabular}




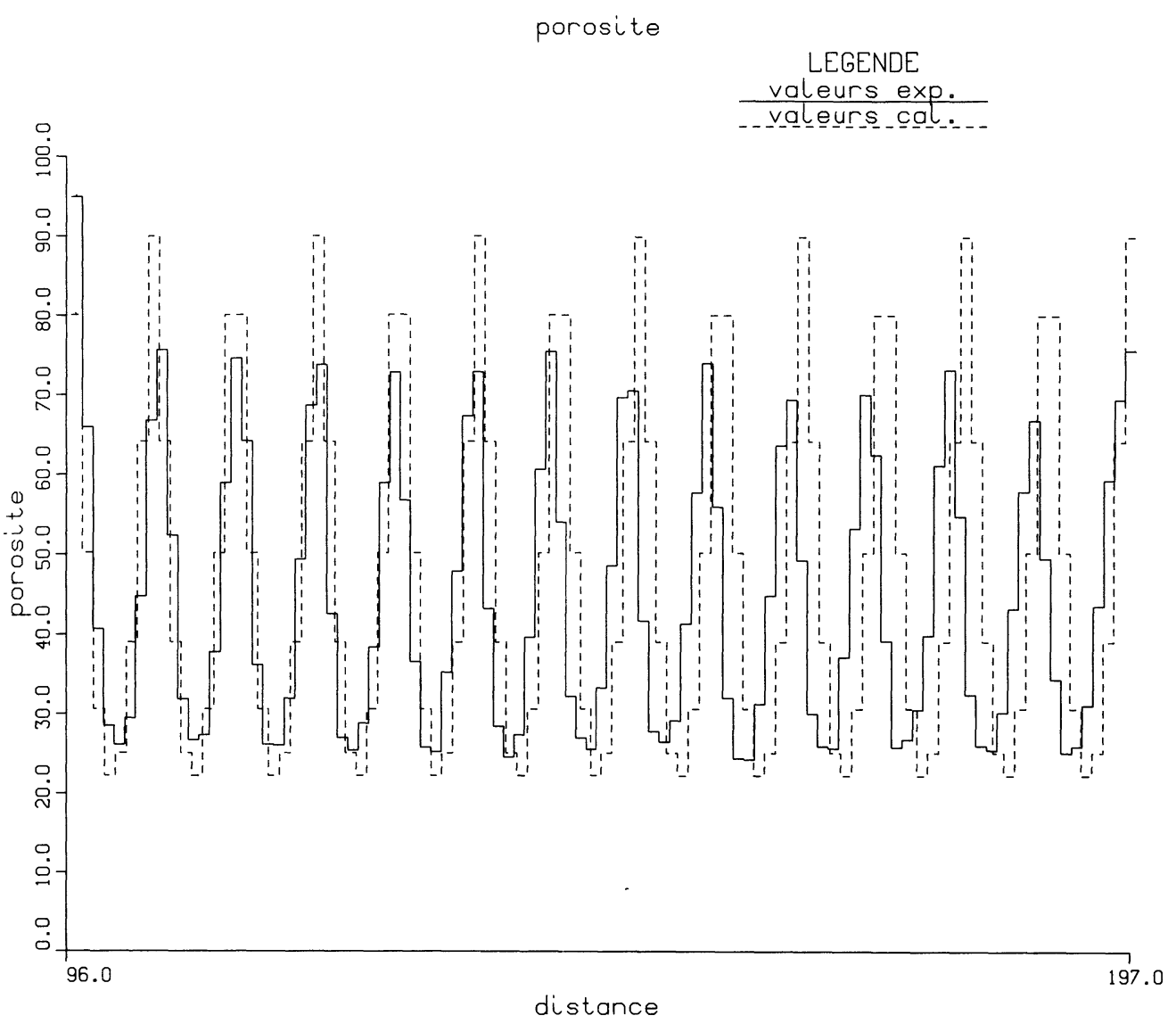

Fig. 5. - (---) Local theoretical porosities and (-) those measured by MRI.

protons remaining in each sample after a $45^{\circ}$ pulse. The results obtained showed a good correlation between the two methods.

\section{Application to deep bed filtration.}

RECALL. - Flow study in solid particle suspensions inside porous medium is a field of fluid mechanics which has many applications. Among these are water purification by sand filtering and clogging in oil petroleum wells. One of the principal question is, how do particles clog and settle within the porous matrix of a given well ?

In the past, the visualizations have been studied with regular porous media [15-17]. In fact, however porous media are irregular and therefore have different sizes pore. Recently, a new procedure has been developed using a transparent micromodel and a video camera for observing microparticle displacement and pore clogging during suspension flow in an irregular porous medium [18]. However, all of these studies have been conducted uniquely with 2-D experimental cells. It would seem important to check that IRM can offer 3-D information.

MODEL. - The model consists of a cylindrical column $40 \mathrm{~mm} \times 40 \mathrm{~mm}$ filled with 2 and $6 \mathrm{~mm}$ diameter glass beads randomly arranged. The porosity measured by weighing was 0.4 . Firstly we performed a section with an image of $256 \times 256$ matrix (resolution $0.7 \mathrm{~mm}$ and thickness $3 \mathrm{~mm}$ ) along the axis of the Soltrol saturated medium. The acquisition time for the image was $13 \mathrm{mn}$. Secondly, we made a homogenous injection, through a network of capillaries at the upper part of the sample (Fig. 6), of a

Injection réseau de capillares

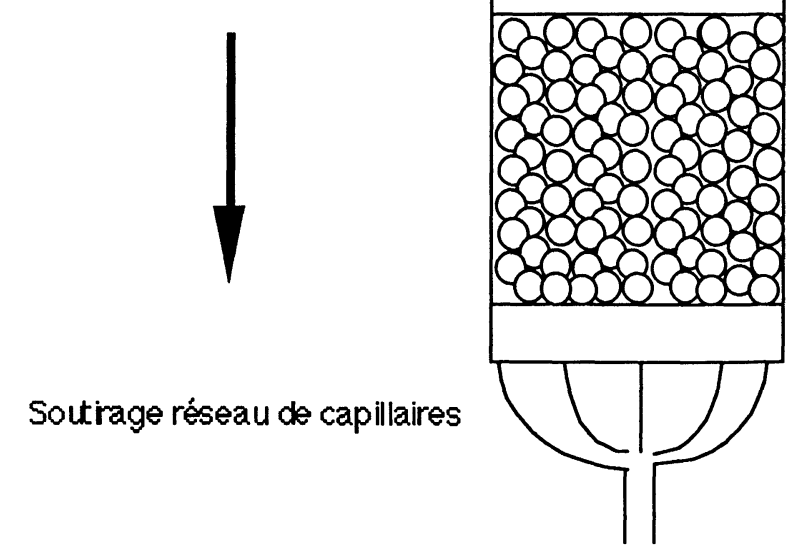

Fig. 6. - Model used for deep bed filtration. 
suspension of rilsan particles of sizes between 60 and $120 \mu \mathrm{m}$ in a Soltrol vehicle. Another network of capillaries at the lower part allowed the evacuation of the volume of Soltrol injected. After $10 \mathrm{mn}$, injection and evacuation of the suspension were stopped simultaneously and we performed a section identical to the first with the same settings of the apparatus and the same measurement parameters. The sample was held in position by 2 parallel bars to prevent any mouvement inside the apparatus.

RESUlTS. - The section images before and after filtration are given in figure 7 . The brightness spectra correspond to a volume of $0.7 \times 40 \times 3 \mathrm{~mm}^{3}$ shown on the images by white lines. Considering the number of peaks and the size of particles, we can assume that the images give pore by pore information. We analyzed lines at 3 distinct heights : 1 , 1.3 and $3.7 \mathrm{~cm}$ from the upper surface. Figure 8
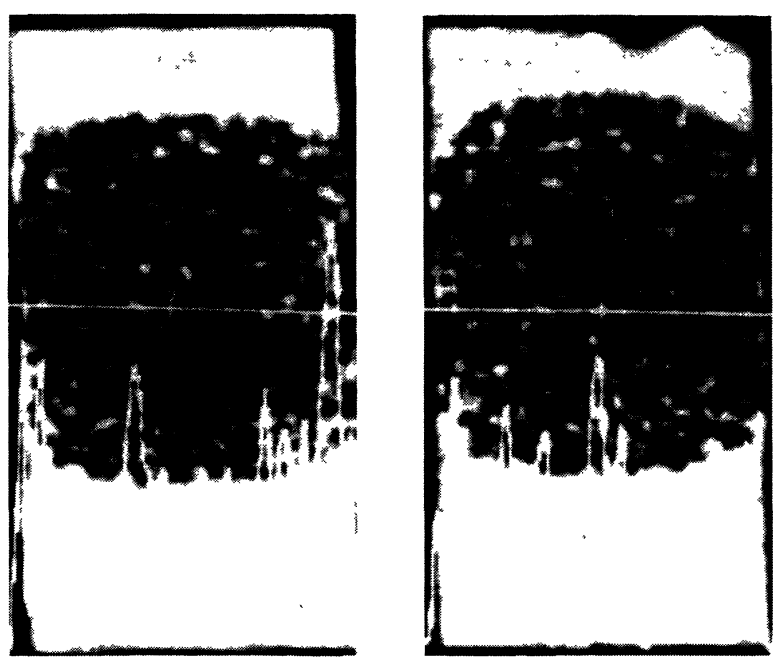

Fig. 7. - Section images with brightness profils before filtration and after filtration.

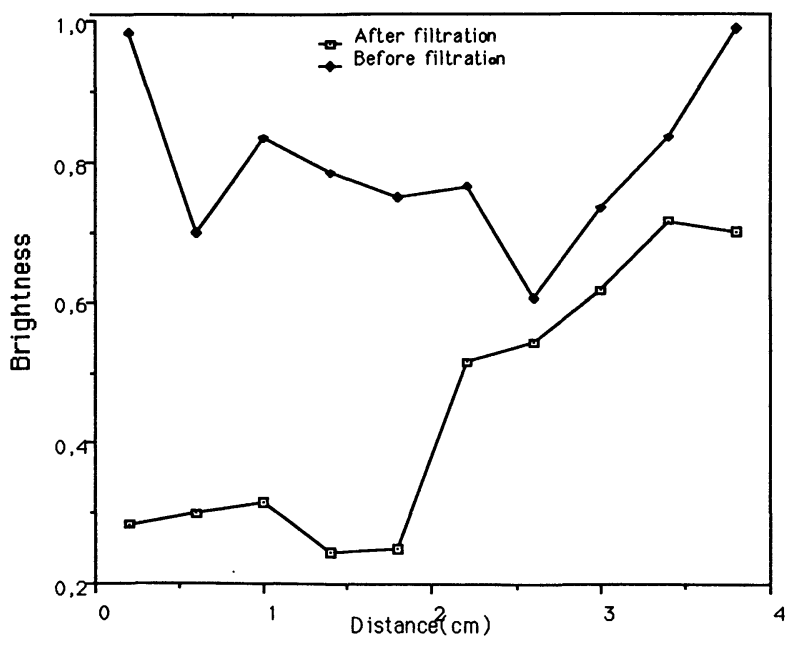

Fig. 9. - Brightness against the depth of penetration.
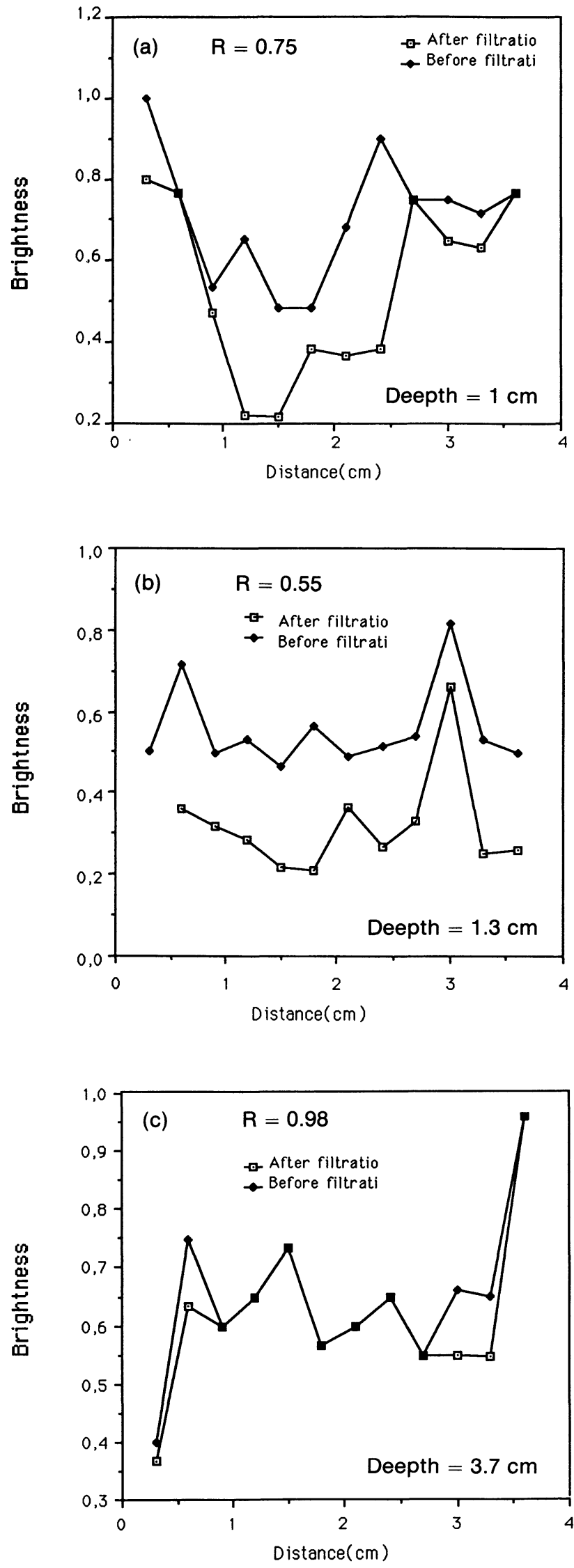

Fig. 8. - Brightness profiles before and after filtration for the 3 heights $(1,1.3$ and $3.7 \mathrm{~cm})$. ( $R$ is the ratio of the local porosity after filtration to the local porosity before filtration.) 
gives the brightness profiles before and after filtration for the 3 heights. We observed :

- inhomogenity of pore clogging;

- greater clogging in the upper part of the porous medium.

Figure 9 gives the oil density against the depth of penetration. The measurements were made from the images by calculating the density of oil contained in a $4 \mathrm{~mm}$ circle. The shape of the curve shows greater particle deposition at slight penetration depths.

\section{Conclusion.}

We tested the aptitude of an MRI scanner to study porous media with a pore size greater than image resolution. Image restitution was noted to be qualitatively good making information available at the scale of the pore. Porosity measurement by made NMR corroborates that by weight. The improvement of the MRI porosity results would require steeper and more linear gradients. The MRI study of deep bed filtration allowed us to check that this method does give 3-D information. Work is underway to complete the characterisation of the scanner used in this study by selecting materials with structural properties and arrangements which are known with accuracy and which are composed of particles whose size is similar to or much lower than the image resolution.

\section{References}

[1] Timur A., J. Pet. Technol. (June 1986).

[2] Cowgill F. D., Pitman, J. K., Seevers, D. O., SPE/DOE (May 1981).

[3] Cynthia E., Williams E., Fung B. M., J. Magn. Reson. 50 (1982) 71-80.

[4] Jones D. W., Child T. F., Adv. Magn. Reson. 8 (1976) Acad. Press.

[5] Singer J. R., J. Phys. E. 11 (1978).

[6] Garroway A. N., J. Phys. D. 7 (1974) L159.

[7] Lipsicas M., Banavar J. R., Willemsen J., Appl. Phys. Lett. 48 (1986).

[8] Pykett I., Pour la Science (juillet 1982).

[9] Guillot G., $4^{\mathfrak{c}}$ conférence EPS de l'état liquide sur l'hydrodynamique des milieux dispersés. Arcachon (25 mai 1988).

[10] Rotwell W. P., Vinegar H. J., Appl. Opt. 24 (Dec. 1985) $\mathrm{N}^{\circ} 23$.
[11] Baldwin B. A., Yamanashi W. S., SPE/DOE 148884 (1986).

[12] Hall L., Rajanayagam V., J. Magn. Res. 74 (1987) 139-146.

[13] Chen J. D., Dias M. M., Patz S., Shwartz L. M., Phys. Rev. Lett. 61 (Sep. 1988) N 13.

[14] Bellon E. M., HaAcke E. M., Coleman P. E., AJR 147 : 1271-1281 (Dec. 1986).

[15] STEIN P. C., D.S.C. Dissertation, Massachusetts Institute of Technology Cambridge (1940).

[16]. Maroudas A., Eisenklam P., Chem. Eng. Sci. 20 (1965) 867.

[17] Payatakes A. C., Park H. Y., Petrie J., Chem. Eng. Sci. 24 (1969) 717.

[18] Houi D., Lamrous O., Pradere J., Zarcone C., $4^{\mathrm{e}}$ conférence EPS de l'état liquide sur l'hydrodynamique des milieux dispersés, Arcachon (25 mai 1988). 